\title{
The Singularities of Social Capital in Family Business: An Overview
}

\author{
Atilano Pena-López \\ José Manuel Sánchez-Santos \\ José A. Novo-Peteiro
}


THE SINGULARITIES OF SOCIAL CAPITAL IN FAMILY BUSINESS: AN OVERVIEW

ALL RIGHTS RESERVED 2010, for the first edition in English

(C) Cátedra de Empresa Familiar de la Universidade da Coruña

ISBN (Collection): 978-84-9745-650-0

ISBN (Book): 978-84-9745-581-7

Legal Deposit: C-4040-2010

Editorial Management: Netbiblo, S. L.

Production Management: Gesbiblo, S. L.

No part of this publication may be reproduced or distributed in any form or by any means, or stored in a database or retrieval system, without the prior written consent of the owners of the copyright, including but not limited to, in any network or other electronic storage or transmission or broadcast for distance learning.

Printed in Spain 


\section{Acknowledgements}

The authors would like to thank the Galician Association of Family Business (AGEF), Caixanova, Inditex and

the Spanish Family Enterprise Institute (IEF)

for their financial support. 
- 


\section{Contents}

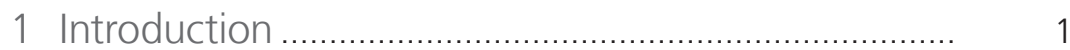

2 Family Social Capital: Interpretative General Models.

3 Values and Social Capital in Family Business

3.1. The Cognitive Dimension of Social Capital ................... 8

3.2. Family Values and Corporate Culture in Family Firms....... 10

3.3. The Family's Ambiguous Relationship with Social Capital ..... 15

4 Networks and Family Firms

4.1. The Structural Dimension of Social Capital ................... 19

4.2. Family Networks and Firm Networks ........................... 20

4.3. Interdependence between both Types of Networks ....... 23

5 Trust and Social Capital in Family Firms

5.1. The Relational Dimension of Social Capital ................... 25

5.2. Bases and Effects of Trust ....................................... 27

5.3. Trust in Family Firms ................................................ 30

6 Evolution and Transmission of Social Capital in Family Firms

6.1. Evolution of Social Capital within Family Companies ......

6.2. Intergenerational Transfer of Social Capital.....

7 Conclusion 
- 


\section{Introduction}

Entrepreneurial networks, family values, altruism, personal attitudes, family commitment, interpersonal dynamics, knowledge transfer, corporate culture or emotional costs are only some of the topics to which the family business literature has paid particular attention in recent years. A common feature of these issues is that they can be analyzed as components of the social capital, a concept that refers to the institutions, norms and networks that promote cooperation and enable collective action.

In our opinion, taking the social capital concept as a reference is a useful analytical device that contributes towards a better understanding of some of the singularities of family firms. The concept of social capital has acquired a growing importance in social sciences in general and in particular, it has recently gained wider acceptance in economics and business administration. Although there is a considerable debate with regard to its nature, most of the theorists on social capital (for example, Coleman, 1990; Putnam, 1993; Torsvik, 2000; Fukuyama, 2000; Adler and Kwon, 2002) agree to define it in terms of its three main dimensions - networks, values and trust- which make it possible for social and economic agents to achieve their goals in a more efficient way. In fact, social capital is a term used to identify the resources present in relationships between individuals. This concept emphasizes the relevance of networks of personal bonds that lay the foundations for relationships of trust, which in turn have their roots in codes of shared values. Following this line of reasoning, this chapter offers a deconstructive analysis of the aforementioned fundamental components of social capital from the perspective of its configuration and interrelation in the sphere of the family business.

With regard to the values, these configure an important dimension of social capital as a mechanism for coordination (amongst other reasons) as they constitute the foundations and support for the trust and the networks. The members of the 
family who work in a family business can play three different roles: as members of the family, as owners, and as managers. It is precisely the superposition of these sub-systems that explains the vital role played by the core values of the family business to the extent that such superposition may create a conflict of values in the decision-making process. Consequently, values and norms should be considered in order to explain the mechanism linking family's social capital to the development of the family firm's social capital.

With respect to the networks, seen as a set of associated norms and resources that convert them into links or bonds of commitment, these facilitate cooperation and coordination between the individuals who form a part of the networks, as they reduce the uncertainty and the transaction costs. Due to the fact that the family business actually comprises two institutions, the family and the business, it is especially interesting to study the coexistence of two interrelated forms of social capital, as a relationship-based network, and a network of commitment.

Finally, trust leads to a reduction in the uncertainty that characterizes the relationships of interdependence between individuals, and it is defined by the existence of mutuality or a link of interdependence of the utility functions. As Uzzi (1997) proposes, the heuristic process of decision making is saved through mental resources, so that the existence of trust and relational overlaps facilitates it, reducing the transaction and information costs, and saving the resources necessary to supplement private norms (coercion, monitoring, etc.) In this sense, the fundamental question to be explored refers to how family relations generate an unusual motivation, bonds of loyalty to the business, increasing trust and contributing towards the creation of social capital.

In summary, the aim of this chapter is twofold. Firstly, to assess the special interaction among the three components of social capital in a family firm. Secondly, to clarify the complementary role of family social capital and organizational social capital. The relevance of this approach based on the theory of social capital is clear because, among other things, it makes 
it possible to shed light on two fundamental questions: firstly, how the specific feedback between the social capital of families and that of family companies may be at the root of the fact that these have higher provisions of social capital than non-family businesses. Secondly, taking into account the differentiation between positive and negative social capital along with specific elements of the components of the social capital in the case of the family business, to what extent it may be concluded that this is a competitive advantage for this kind of business.

The structure of the paper is as follows. The chapter starts in Section 2 with an introduction to the interpretative general models of social capital dimensions in order to understand the ways in which these dimensions interact. In Section 3 we explore the cognitive dimension of social capital, the values, and its role as a determinant of corporate culture. Section 4 examines the family firm network and its main components and interactions. Section 5 analyzes the role of trust in the context of the family enterprise. Section 6 discusses the main implications of the analysis in terms of the evolution and the intergenerational transmission of social capital in family firms, and Section 7 concludes the paper.

\section{Family Social Capital: Interpretative General Models}

The specificity of family firms, i.e. the systematic interaction between the family and the activity of the enterprise, creates particular resources and capabilities. Resources are goods and attributes present in this type of companies, while capabilities are a special type of resources inherent to the organization, which are non-transferable and lead to improvements in productive efficiency (Habbershon, 2003).

Social capital theory constitutes a suitable explanatory framework for this specificity (Pearson et al., 2008) insofar as 
it generates a conceptual framework from which to analyze the generation and effects derived from the social relations. As Arregle (2007) points out, the special development of family social capital is associated with four factors: stability, interaction, interdependence and closure. These factors, particularly characteristic of family enterprises, result in an organizational capital in which the social networks of the family and the company are overlapped, generating an isomorphism and collective identity. Using a wide definition, social capital is seen as "relations between individuals and organizations who facilitate the action and create value" (Adler and Kwon, 2002). However, a model of the family social capital (which overcomes the "black box" perspective) would have to consider the causal links between the three characteristic dimensions: structural, cognitive and relational (Nahapiet and Ghosal, 1998; Pearson et al., 2008).

The structural dimension is defined by social interactions, i.e. the density and strength of the existing connections, linked to the ability to take advantage of these networks. In the case of a family company's "organization" the concept of "the appropriable organization" is particularly important. This term was coined by Coleman (1988) to express the capacity of an organization to transfer the networks from one individual to another. In our case of analysis, the structural bonds of the family make it possible to extend the links of the organization, guaranteeing their transferability and appropriation.

The cognitive dimension includes representations, interpretations and systems of meanings between the members of an organization (Nahapiet and Ghosal, 1998). A unique language, history and culture ensure communications that integrate the company. As Lansberg (1999) states, the family enterprise culture and history in common grant a special sense to the type of activity carried out that favors cooperation.

Finally, the relational dimension is reflected on the existing levels of particular or general trust between the members of the company. One of the main features of a family company 
is a high level of mutual trust, which results in a reduction of transaction costs and monitoring.

In spite of the conceptual clarity of this division, it is necessary to briefly explore the causal links between them. General models on social capital in family firms differ particularly in the proposed causality between the first two dimensions and the relational dimension. For example, Tsai and Ghoshal (1998) propose that the structural dimensions are an antecedent of the cognitive dimensions; consequently, personal interactions lead to the generation of values. In the same sense, the cognitive dimension constitutes the antecedent of the relational dimension. A cognitive shared vision, therefore, finally leads to the generation of interpersonal trust, diminishing opportunistic behavior. In this way, the structural and cognitive dimensions are antecedent of the relational dimensions, and priority would be given to the structural features of the firm (Pearson et al., 2008) (Figure 1).

Figure 1: Causal links between social capital dimensions.

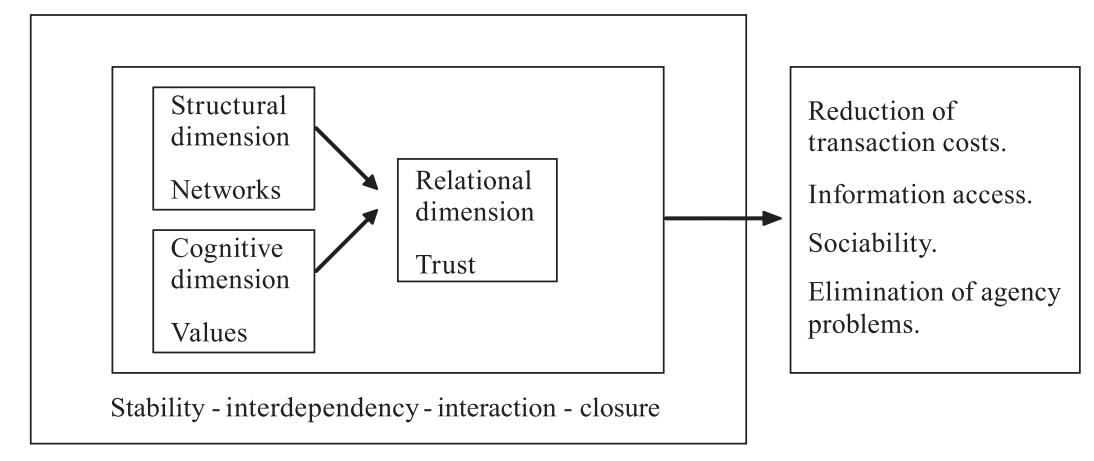

Source: Pearson et al. (2008).

However, this proposal is open to criticism. From Uphoff's perspective (1998), only two major dimensions can be distinguished in social capital: structural and cognitive. As in the previous model, the former reflects forms of social 
organization, rules, procedures and networks that contribute towards cooperation, whereas the latter alludes to mental processes, norms, values and attitudes. Both dimensions reduce the transaction costs and facilitate cooperative behavior. These dominions are intrinsically linked, since although the structures and the norms and values can be analyzed independently, both are cognitive and the only difference lies in the observability of the first. At the same time, these two dimensions are actually bound in social sciences to another subjective phenomenon: expectations (Figure 2).

In the structure, the roles and behaviors are caused by expectations and a system of values or norms that support the structure justifying these expectations. As a result, structures, norms and values affecting the behavior of individuals generate expectations regarding how an individual should act within a network. Those expectations can be interpreted directly in terms of trust, which is also essentially of cognitive nature.

Figure 2: Uphoff's proposal

on social capital causal links.

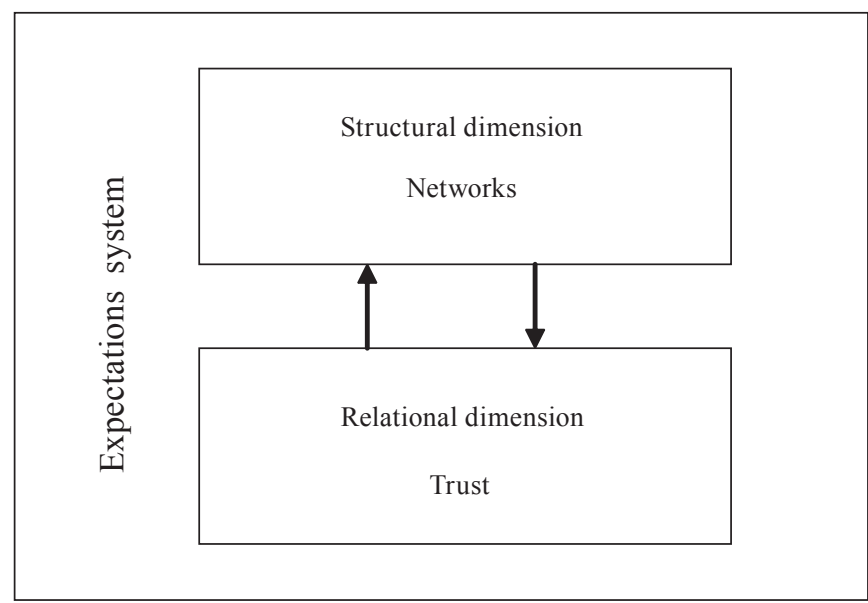

Source: Authors' own elaboration from Uphoff (1998). 
Consequently, Uphoff's perspective questions the causality proposed by the previous general model. This is a cognitivist interpretation of social capital, focused on the concept of expectations, where the differentiation of dimensions is exclusively in their objective character. Considering this reframing, and from our point of view, the most reasonable vision of the interrelation is circularity (Figure 3). In this case, it is not possible to include the structures without the relational bonds of trust, and the latter without the existence of underlying value systems.

In economic terms, social capital and its expression in the family firm is also a form of cognitive economy that is mainly materialized in what we could call a "trust economy". As Uzzi (1997) proposes, the heuristic process of decision making is saved through mental resources, so that it is facilitated through the existence of trust and relational overlaps, reducing the transaction and information costs, and saving the necessary resources to supplement private norms (coercion, monitoring, formation of rules, etc.).

Figure 3: Circular causal links of social capital.

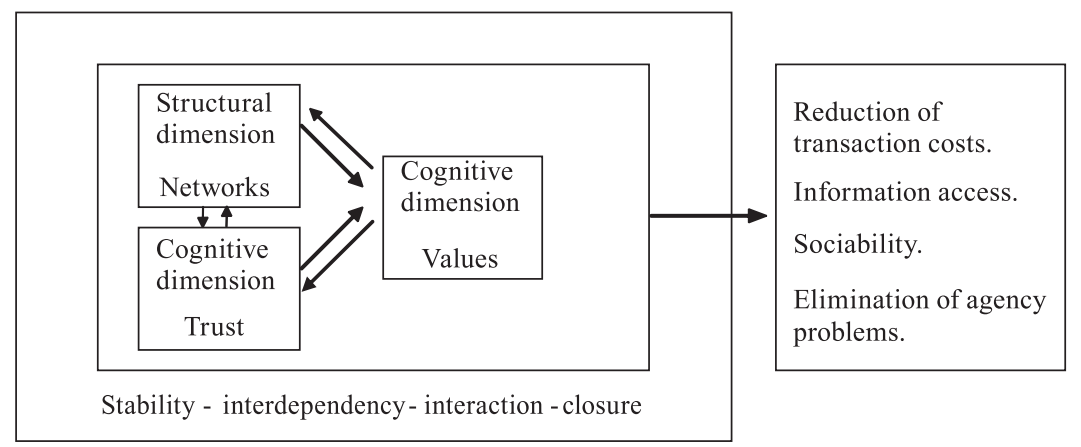

Source: Authors' own elaboration.

Altogether, entrepreneurial social capital is essentially a cognitive system which can be interpreted in terms of expectations and 
trust in the behavior of the members of the company. This can be considered the eminent dimension of the social capital. Consequently, the system can be analyzed on the basis of any of its three dimensions: the formal and informal structures, the underlying values and interpersonal trust. Obviously, the existing values and networks influence the trust levels, yet the structures cannot be included without understanding the levels and characteristics of the existing trust and the common values shared by its members. In the following parts we will deal with these dimensions separately, although we will consider their joint evolution based on this circular causality.

\section{Values and Social Capital in Family Business}

\subsection{The Cognitive Dimension of Social Capital}

When adopting a perspective based on a cognitive dimension, social capital is inextricably linked with the production and maintenance of a set of shared values or paradigms that permit a common understanding of appropriate ways of acting (Nahapiet and Ghoshal, 1998). In this case, Uphoff (2000) develops a conceptual model in which the cognitive dimension of social capital is derived from mental processes and resulting ideas, reinforced by culture and ideology, specifically norms, values, attitudes, and beliefs that contribute cooperative behavior and mutually beneficial collective action. More recently, Pearson, Carr and Shaw (2008) argue that the cognitive dimension of social capital comprises the group's shared vision and purpose, as well as unique language, stories and culture of a collective that are commonly known and understood, yet deeply embedded. As such, the cognitive dimension of social capital is unique in family firms, as it is often deeply embedded in the family's history. 
In particular, values are an important dimension of social capital as they are the foundation and sustenance of trust and networks. Inasmuch as sharing values can promote harmonious relationships and trust mechanisms to allow a firm to be more productive, is important to analyze the role that values and, in particular, the rules resulting from them play in generating trust (and ultimately network instance), which in turn is part of the social capital as a coordinating mechanism. This form of trust exists when one "thinks and feels" in the same way as another due to shared norms or values (Fukuyama, 1995) that may be based on common kinship, familiarity, background or interest (Lane, 1998). In fact, according to the definition of Putnam (1993), one of the forerunners in the empirical analysis of social capital, norms are the unwritten rules of conduct of a certain group of people. Indeed, these types of norms are the concrete elaborations of the group's values, which are the abstract, ethical principles that lie at the roots of cultures.

According to Arregle, Durand and Very (2004), one aspect that distinguishes the family firm from other companies is that their capital is influenced by the social capital of the company owner ("familiness"). Therefore, the family has a direct impact on the establishment of corporate social capital insofar as it contributes strongly towards shaping the behavior and thought patterns of its members. From this point of view, it is worthwhile to understand which dimensions of family values are most persistent and have the biggest impact on family business. Furthermore, values, norms, attitudes and beliefs that qualify as social capital are built up over time, but can be diminished and even destroyed in a relatively short period of time. That which has been accumulated can be lost subsequently through a variety of uses or misuses. For these reasons, it is important to focus on the role of values in creating social capital which is specific to the family business and, secondly, on the influence of values on the interaction between family social capital and the company. Both aspects 
are important as they affect the ability of family businesses to create their own competitive advantages or disadvantages.

As a starting point for addressing these questions, it is necessary to clarify a series of aspects regarding family values, the singularities of the culture of family firms, and the possible contradictory roles of family values as source of the social capital of firms.

In this line, Bubolz (2001) points out that the family both uses and creates social capital. Moreover, depending on their characteristics, the family creates social capital that will have more or less beneficial effects for their members. On the one hand, from a positive point of view, such aspects are often seen in this field as commitment, support work, solidarity and altruism that the family offers. In fact, the family, like any other institution, enables one of the most prized social values: altruism. Although altruism can occur in other areas, it is certain that only family can be considered an ethical obligation. As family relationships continue, increasing interdependence and interactions produce greater levels of trust (based on shared norms and values), principles of reciprocity (obligations) and exchange among family members. On the other hand, and more negatively, it should be noted that in a context which is greatly influenced by tradition and custom, the "wisdom" suggests that conventional family businesses are typically autocratic, inflexible, unclear in their direction and reluctant to invest in people.

\subsection{Family Values and Corporate Culture in Family Firms}

Commitment to any group or community requires a set of shared values, norms and meanings, as well as shared history and identity. Value systems help to shape this set of shared symbols that promote collective identity. This aspect becomes especially relevant in a family setting because for families, core values are 
typically their first priority. In particular, family values may play an important role in shaping the organization of business and their efficiency. In order to explore the question of whether typical family values help shape a culture of family businesses in order to promote a stronger and better performance, it is necessary to consider certain aspects with regard to family values.

Although no unique and universal hierarchy of values exists, it is possible to assume the persistence of certain social values associated with the family. Kepner (1983) explores different types of family systems and notes that a family can be characterized by how they manage conflicts and differences, individualism, emotional expression, the acceptance of change, separation and so on. Meanwhile, Olson (1986) characterizes different family systems in terms of two dimensions: their cohesion and adaptability. He distinguishes four levels (from weak to strong) of each dimension. In fact, families at the ends of each of these dimensions have problems, while more balanced families seem to work better.

According to the institutional perspective, the family is an institution that contributes towards shaping the attitudes and behavior of its members and, therefore, it has a direct impact on the generation of social capital of the company. Bourdieu (1994) refers to a kind of "family spirit" that makes family members behave as a collective agent and not as a mere aggregate of individuals. Because children receive their primary socialization from their family during childhood (Berger and Luckman, 1967), stability in terms of time spent under the family's influence is present in many family settings. Increased family stability enhances the understanding of the values, behavioral norms and cognitive schemes used by family members. This understanding facilitates the integration, cohesion and survival of the family unit (Bourdieu, 1994).

Generally speaking, culture refers to the values shared by people as members of a group and which tend to persist over time, even when group membership changes (Kotter and Heskitt, 1992). This characterization of the values and norms as 
constitutive elements of culture is transferable to the business world and, from this perspective, it is impossible to deny the relevance of values in shaping corporate culture, especially the core values of the founding entrepreneur. In fact, the culture within family-owned firms, in which family members have a shared vested interest, leads to the perception of common values and trust among members.

Based on the premise that corporate culture influences, among other things, efficiency in management, it could be possible to envisage the extent to which values and rules of the family institution can contribute towards creating a sustainable competitive advantage, in the sense that the culture which takes shape within a family firm is different from that of other companies, and is also difficult to replicate.

Following this line of analysis, one of the main questions to be asked is to empirically verify the existence of differences in values between family and non-family firms. Denison, Lief and Ward (2004) show that the dominant role of the founder, not only during the period of "entrepreneurship", but also potentially through successive stages, values and motivation of the owner, are powerful "cultural drivers". Within this framework, loyalty to the beliefs and core values of the founder acquires a special relevance. According to these authors, family businesses are in a unique and enviable position due to their link with strong beliefs and core values. In this case, the role of the founder is crucial to establish the identity, the basic beliefs and the raison d'être of the organization. Specifically, according to the findings of Denison et al. (2004), two aspects of consistency - core values and agreement,- appear to represent distinct advantages in family businesses. If we add to this the fact that the specific culture of the company (usually rich in core values) is supported by its founding family which has nurtured it for generations, it is difficult to replicate and, therefore, can be a source of strategic advantage.

In a more recent work, Vallejo (2008) provides some empirical evidence suggesting that the corporate culture of family businesses is different from non-family firms. To test 
this hypothesis, the author identifies the specific set of values whose presence in the family business culture becomes a distinguishing feature:

Firstly, the importance and weight of commitment is greater in family businesses. To this end, he distinguishes three types of commitment: affective (emotional attachment and identification with the organization), calculative (based on the recognition by employees of the costs associated with leaving the organization) and normative (sense of loyalty to an organization and the internal conviction that loyalty is important). Secondly, the existence of better human relations within the company and a better working atmosphere, and that this harmony is one of the characteristic values of the family business. Thirdly, the trend among family businesses to target their activities toward the long term (Long-term orientation) in contrast to non-family businesses. Family businesses tend to have goals with a strong, intrinsic sense of security (Family Safety) together with the vision of the company as a legacy to be passed on to successive generations, leading to a management style that is highly geared towards the long term. Finally, the dedication and concern for the client (customer service) as a value is also considered a key element in the competitive strategy of family firms.

Ultimately, the results of Vallejo (2008) indicate that a values-based model can help the company survive several generations, which is one of the most important challenges for family businesses.

These results are consistent with the approach of Dumas and Blodgett (1999) who define the core values of family businesses, and explain how those values can guide the family business in decision-making and improve their efficiency. These authors analyze 50 family businesses around the world and identify the following as the most prominent core values: quality (42\%); commitment (25\%); social responsibility (20\%); fairness (18\%); respect (14\%); integrity (12\%); honesty (6\%). Davies (1997) identifies honesty, integrity and accountability as core business values. Along the same lines, a well-established 
trend in the Harvard Business School emphasizes the ability of the ethical values of justice, honesty and trust to influence both individual efficiency and organization.

Dumas and Blodgett (1999) conclude that after the family firm defines its core values, it is important that it articulates these core values in its mission statement, as a clear definition of these values can guide the family firm in decision-making. In fact, failing to consider core values may seriously impair decision-making statements of how to apply values in everyday life that guide the business towards more consistent ethical behavior, and allows for more effective decision-making that can have a positive impact on the bottom line. Problems arise when a family member expects people in the business to operate according to the rules used in the family realm and vice versa. In contrast, however, the values, ideals and sense of purpose nurtured by the owning family are potentially a vast source of strength and energy for the business. According to Aronoff and Ward (1995), a healthy owning family with strong values may in fact be the greatest resource a business can have.

Arregle, Hitt, Sirmon and Very (2007) contribute to the analysis of family firms' uniqueness by suggesting a theoretical framework that can be applied to family firms, to the extent that they are organizations characterized by a dominant family with its own values and behavioral norms, and with a strong commitment to the organization. From this point of view, values and norms could be important elements that must be considered in order to achieve a better understanding of the mechanism linking Family Social Capital with the development of the family firm's Organizational Social Capital. In this field, more research needs to be carried out in order to assess the relevance of cultural explanations for family firms and the exact mechanism through which family values affect firms. It would be of particular interest to understand which dimensions of family values are most persistent and have the biggest impact in family business. 


\subsection{The Family's Ambiguous Relationship with Social Capital}

Family values may play an important role in shaping the organization of businesses and their efficiency. The social case for family values appears to be underpinned by a presumption that the core values are commitment, solidarity, altruism, etc. However, family values are also associated with factors such as nepotism, autocracy or inflexibility. This would be the "dark side" of family values that matches the "dark side" of social capital. Therefore, apart from the beneficial aspects, there are also negative aspects of social capital that are also worth mentioning. In general, the negative manifestations of social capital include four major types: exclusion of those outside the group, the excessive demands of solidarity and mutual aid among group members, constraints to individual freedom and the rules that hamper the development of individual members (Portes, 1998).

One factor which is often lacking in the assertions about the potential of family values to build social capital in a family firm is a rigorous examination of the nature and quality of any social capital that may result. Indeed, in discussions of social capital, the focus of attention is most commonly on "social connectedness", and therefore on the debates regarding bonding (exclusive ties of solidarity between individuals of a same group), bridging (links between different groups) and linking (links between individual/groups and any form of authority) (Woolcock, 2001). Actually, many family firms tend to produce bonding as opposed to bridging or linking social capital. This can be seen as problematic because in simple terms the bonding form of social capital is exclusive, whereas the bridging form is more inclusive. That is, the family (and family values) is generally recognized as playing a significant role in building bonding capital. The opportunities for bridging capital are less clear, and linking capital is likely to be more limited. 
Therefore, it should not be overlooked that the role of values is ambiguous. On the one hand, they promote the internal cohesion of the group. However, on the other hand they hinder cooperation with those groups who do not share the same values. According to Parsons' well-known distinction between particularistic and universalistic values (1949), the former foster internal cohesion but hinder cooperation with out-groups. Particularistic values promote solidarity and at the same time segregation. Family values, for example, confer social cohesion and solidarity to members of one family, while segregating non-members. All people experience both types of values simply by belonging to social circles of different extent. The feeling of belonging to a businessman's family is due to particularistic values, while the need for cooperation with the wider environment requires universalistic values.

The idea that a culture based on strong family ties may impair economic efficiency can be found in Weber (1904). This author argues that strong culturally predetermined family values may place restraints on the development of capitalist economic activities, which require a more individualistic form of entrepreneurship and the absence of nepotism. In a similar line, Banfield (1958) focuses on the concept of "amoral familism" as one of the main reasons for the smaller average firm size and slower economic development of the south of Italy in comparison to the north. In his study of families in southern Italy, he identified a potential trade-off between trust among the narrow realm of kinship networks and trust in the society at large. A similar argument has been developed by Fukuyama (1995), who proposes that in societies where people are raised to trust their close family networks, they are also taught to distrust people outside the family, which impedes the development of formal institutions in society.

Continuing this line of reasoning, Bertrand and Schoar (2006) conclude that a culture based on strong family ties can give rise to nepotism. If founders derive utility from seeing relatives involved in the business, they may decide to hire key 
managers from within their kinship network rather than turn to more talented professional managers. Beyond the direct effect of these lower-quality appointments on performance, nepotism may also have adverse spill-over effects, whereby it creates negative incentive effects throughout the organization. If lower-level employees know that promotion decisions are not tied to performance, they may be less willing to make greater efforts or to remain within the family business, thus making it more difficult to retain talent.

Family values can also create efficiency distortions if they introduce non-monetary objectives into the founder's utility maximization that go against optimal decisions for the business. Zellweger and Astrachan (2008) show that the non-financial aspects of organizational ownership are particularly relevant in the context of privately held family firms, as it is widely acknowledged that most family firms deliberately strive for a mix of pecuniary and non-pecuniary performance outcomes (Westhead and Cowling, 1997). Ward (1997), Sorenson (1999), Sharma, Chrisman and Chua (1997), Anderson and Reeb (2003) and Corbetta and Salvato (2004) consider independence, tradition, and continuity as common examples of these nonpecuniary outcomes. Moreover, most of this literature is essential in order to gain a better understanding of how these non-financial aspects are actually endowed and valued by owners within the context of the family firm.

Perhaps most symptomatic of the cultural constraints within family firms are the inheritance rules that govern many of them. These inheritance norms vary from strict primogeniture, where the oldest son inherits everything, to equal sharing rules among all the sons of the founder. The main point is that rigid inheritance rules may have direct cost for family business (Bertrand and Schoar, 2006). Furthermore, in line with the cognitive dimension of social capital, the role of codes and language in relationships development is essential (Nahapiet and Ghoshal, 1998). Therefore, what may constitute a risk factor is a situation in which the successor's "system 
of representation" may differ from the standards, values and beliefs to which family members adhere.

Based on the approach of Dumas and Blodgett (1999), it is useful to consider family businesses as a structure set of three subsystems with their own (individual) needs, expectations and responsibilities: ownership, management and family. Each of these elements tends to have different goals and expectations. Individuals may belong to more than one group simultaneously. This means the family members working in family businesses can play three different roles: as parents, as owners and as managers. In family businesses, this overlap may create a conflict of values when making decisions about hiring, firing, promotion and discipline. The overlap of these subsystems is what explains the vital role played by the core values of the family business. Most dilemmas in family businesses arise when the needs or priorities of the family differ from the needs of the company. Problems arise when a family member expects people in the company to act in accordance with the standards used in the family and vice versa. In contrast, the values, ideals and sense of purpose encouraged by family ownership may be an important source of strength and energy to the company.

In summary, it is not just question of the nature of common values that family firms promote, but whether these values are likely to generate what is known as "positive social capital". For this reason, families have to be successful in this if they are to avoid what Putnam (1993) refers to as "dark capital", the kind that may be very beneficial to a small group (the family) but highly damaging to outsiders. According to Paldam (2000), the outcome of this kind of discussion is that when social capital has been successfully measured, and its effect is analyzed, one may reach disappointing results. Indeed, social capital in family firms may turn out to be conservative or even harmful in some cases, even if it is productive and benign in other cases. 


\section{Networks and Family Firms}

\subsection{The Structural Dimension of Social Capital}

One of the most widely agreed meanings of the term "social capital" identifies this concept with the density and stability of a social network. As indicated by Durlauf and Fafchamps (2004), social capital may be defined as resources embedded in social networks that are accessed and used by actors for actions. Nahapiet and Goshal (1998) define social capital as "the network of relationships possessed by an individual or social unit, and the sum of actual and potential resources embedded within, available through, and derived from such a network".

A network is comprised of agents (individuals and/or organizations) who are connected by some type of link which allows them to exchange resources. The ultimate goal of the network is to facilitate cooperation and coordination by reducing uncertainty and transaction costs. The networks are mainly connected with two dimensions of social capital: the relational dimension, which refers to the relationships between the network members and groups, and the structural dimension, which identifies the general or architectural characteristics of the network.

This concept has three basic components: (i) the members of the network, i.e. the possessors of social capital; (ii) the resources embedded in the network, i.e. the resources which are exchanged or transferred through the network; and (iii) the links or kind of interactions among members, i.e. the mechanism through which members are connected and interact. In the first approach, we find that a family firm network includes several types of members, fundamentally family members but also some friends and some workers who may belong to the family network if a close relationship exists; links are mainly parental, but may also include friendship and stable professional relationships; and finally, resources including a wide variety of elements such as information, specific knowledge, values and trust. 
Coleman (1988) establishes a number of important dimensions of network configuration, and Salvato and Melin (2008) adapt them to the context of family firms' social capital. These dimensions are network centrality and network closure. Network centrality refers to the extent to which the "central" individuals have ties throughout the network and thus enjoy a broad span of influence, while network closure is the extent to which all actors in a network have relationships with one another. Another important feature of the architectural dimension of social capital is appropriable organization that captures the extent to which networks created for one purpose may be used for another. Network centrality is a concept that can be related to the concept of founder centrality. This concept was developed within a family firm by Kelly et al. (2000) (see also Athanassiou et al., 2008). These authors suggest three dimensions of centrality: "betweenness" (central to the flow of information), closeness (direct links with the top management group) and connectivity (the ability to influence the most connected members).

This description led to the establishment of a fundamental distinction between family networks and organizational or family firm networks. In other words, family business "constitutes family and business systems interpenetrating one another and when one looks at a family firm, one is really looking at the interaction of two complex social systems" (Lee, 2006). Or, "family firms are unique in that, although they work as a single entity, at least two forms of social capital coexist: the family's and the firm's" (Arregle et al., 2007).

\subsection{Family Networks and Firm Networks}

\section{(i) Family Networks}

Family networks are formed on the basis of the existing relationships between family members. As mentioned in Section 2.1, the family is the primary source of social capital by providing aspects such as education, values, information or the transfer of knowledge. 
Hoffman, Hoelscher and Sorenson (2006) introduce the concept of family capital as a special form of social capital which is limited to family relationships. These authors point out that this concept is limited to the structural and relational components of social capital. Thus, family capital firstly refers to network ties in terms of information channels among family members, and secondly, the obligations and expectations, reputation, identity and moral infrastructure of the family. It is interesting to note that information channels are considered social networks within the family and the family business and also are the mechanisms that connect them to the outside world. In other words, family capital includes internal and external information channels.

Lee (2006) considers two specific characteristics of family relationships in order to document the influence of family relationships on the outcomes of family business: family cohesion and family adaptability. Family cohesion refers to the degree of closeness and emotional bonding experienced by the members in the family. Family adaptability is defined as the ability of a family system to change its power structure, role relationships and relationship rules in response to situational and developmental stress.

\section{(ii) Firm Networks}

Firm networks arise as a result of the fact that entrepreneurs engage in stable exchange relations that provide a context of cooperation. Anderson and Jack (2002) point out that social capital is more than everyday interaction in the context of entrepreneurial networks: "agents seek to build a picture of each other and use it to locate each other in some wider scheme: social capital is a relational artifact but can be described as a quality of a relationship". Entrepreneurial networks are "complex mixture of multiplex social and professional ties, all of which tend to contain both affective and instrumental elements, bonded by trust" (Anderson, Jack and Drakopoulou, 2006). In this sense, "networks can provide 
both, access to resources and a predictable environment for social and economic exchange activities" (Bowley and Easton, 2007). In fact, it can be said that the survival and success of a firm often depend on an entrepreneur's ability to establish a network of relationships.

Granovetter (1973), Anderson, Jack and Drakopoulou (2006) distinguish between two types of network ties in an entrepreneurial network: strong ties and weak ties. The first type include "network contacts are those people with whom the entrepreneur has a close personal relationship, and with whom he or she interacts quite frequently" and they are family and friends. The second type "are more distant emotionally and may be activated only infrequently". These authors underline the fact that strong ties have been found to provide very highquality resources - especially information - which is often not commercially available and is very well focused on the specific needs of the entrepreneur and the business. However, because family and friends tend to move in the same circles as the entrepreneur, these resources may not offer much beyond the entrepreneur's own scope; that is, they may not be adequately diverse in nature. In the debate about what kind of tie is more important for a firm, Jack (2005) concludes that "the effectiveness of the network seems to depend upon the presence of both strong and weak ties since different forms of ties are seen to provide distinct and different resources".

A particularly interesting distinction for family firms can be found in Casanueva and Galán (2004). These authors differentiate between two kinds of entrepreneurial networks: those that have formed out of the explicit intentions of the firms concerned, and those networks that have formed without explicit intention, due to a series of historic, geographic, social and cultural circumstances that have led to a set of preferential relations between competing firms, between suppliers and their customers and between firms and institutions. The same authors emphasize the concept of "embeddedness" and distinguish between two types of embeddedness in inter-firm relations: 
structural embeddedness itself and relational embeddedness. The concept is connected with the cohesion of the network, "insofar as it refers to the strength of the direct links and the mechanisms through which firms obtain specific and valuable information. The fact that firms share more direct connections implies that they possess more information in common and more knowledge about the other parties".

One interesting strand for research in this area is the role of family firms and the behavioral effect of interlocking directorates in family firms. Only a few studies have considered this issue, such as Salvaj, Ferraro and Tàpies (2008) and Silva, Majluf and Paredes (2006). Salvaj, Ferraro and Tàpies (2008) point out that the key concept is embeddedness, i.e. the actor's relative depth of involvement in the social structure. The structure of social relations in which a firm is embedded has an important impact in its performance because this structure provides both opportunities and constraints. An interlocking directorate is created when a person affiliated with the board of directors of one organization sits on the board of another organization. The embeddedness of one organization in the corporate elite comes from being tied to other boards through shared directors.

\subsection{Interdependence between both Types of Networks}

From a process perspective, Arregle et al. (2007) investigate mechanisms that link a family's social capital to the creation of the family firm's social capital. Social capital developed within the context of the family can be transferred to the firm by means of four mechanisms: (i) institutional isomorphism, meaning that when a background institution is actively involved in the management of a firm, as is the case of family firms, and it is dependent on critical resources, the firm will tend to be similar to the family in structure, behavioral focus, climate and, as a 
consequence organizational social capital; (ii) organizational identity and rationality, because family members transmit its main characteristics to the firm; (iii) human resources practices, which in general will be determined by the values and norms of family social capital; and (iv) overlapping social networks, because family members involved in the firm generate the firm's initial network structure that in turn influences the development of the family firm's organizational social capital.

These authors, as well as Pearson et al. (2008), examine how factors underlying the family's social capital affect this creation and indicate four factors that act as motivational factors of family social capital within the family firm: (i) stability as a necessary condition for strong social relations to emerge, in a double perspective: family nucleus stability independent of the firm, and the preservation of the firm in the family; (ii) interaction, meaning that frequent and diverse interactions among family members strengthen family social capital and simultaneously contribute towards the development of the family firm's organizational social capital; (iii) interdependence because the firm is often the main asset of the family's collective patrimony, which implies not only an economic interdependence but also a psychological interdependence and emotional costs; and (iv) closure, meaning that only family members can participate in the intra-group network though kinship, although the density of linkages and interactions is family-specific.

Also analyzing the interdependence among different kinds of networks and ties in the entrepreneurial context, Jack (2005) shows that strong ties act as a mechanism for generating knowledge and resources, but are also used to link into wider social contexts and provide a mechanism to invoke apparently weak ties, again connected with the concept of appropriability, whereby a family member's network generates the firm's network, and at the same time the family firm's network can influence the family's network.

The interdependence between both kinds of social networks can also imply dysfunctional and negative consequences. 
Arregle et al. (2007) point out three potential problems that can emerge from a strong family social capital for family firms: (i) overdeveloping organizational social capital as a consequence of ignoring new sources of information, causing dysfunctional power arrangements within the firm, hindering innovation as people are embedded in established practices, etc.; (ii) the transfer of dysfunctional family realities to the family firm's organizational social capital, such as problems of communication or personal conflicts; and (iii) a strong family can inappropriately capture for the family the goodwill intended for the firm by external actors. As Durlauf and Fefchamps (2004) state, it is interesting to note that dense and stable networks can also have negative implications in certain contexts. These authors analyze the required conditions in order for the information sharing, group identity and explicit coordination derived from the existence of social capital to generate efficiency gains in organizations and in the economy as a whole.

In summary, Sharma (2008) points out that both families and firms have stocks of social capital and that the flow of social capital from one to the other is bidirectional, and that the distinctiveness of the stocks of social capital in both a family and a business depend on a balanced flow between them over time. In this sense, an excessive flow and the resulting imbalance can lead to a competitive disadvantage.

\section{Trust and Social Capital in Family Firms}

\subsection{The Relational Dimension of Social Capital}

Despite the high number of studies which have explored the term "trust", the concept is far from being clearly defined (Kramer, 1999). The most influential definitions consider a general attitude or expectation on the behavior of the individuals or the social system in which these are inserted (Luhmann, 1988; Hardin, 2001). In other words, trust in the other is based on a 
belief in their correct intentions, whereby their commitment is to fulfill their obligations, not to adopt opportunistic behaviors and cause damage voluntarily.

From a more psychological point of view, trust is an intention to accept vulnerability on the base of positive expectations of the intentions of the other (Rousseau et al., 1998). Therefore, this concept is directly linked to feelings of security. An atmosphere can be described as secure if everything functions in the way the different actors expect, so that the individuals do not find any problem in carrying out what they do in a routine way. Distrust, on the contrary, is connected with a lack of transparency and the accompanying sense of uncertainty (Schul et al., 2008).

Trust is essential for companies and the economy in general due to its capacity to facilitate the formation of large-scale organizations with agency relations. The expansion of the activity of an organization or the economy in general supposes an increase of the interdependence between economic agents and increase in the division of labor. Consequently, it also involves an exponential expansion of the number of agency relations. In these, a principal must trust an agent for the development of an activity within a context of strong information asymmetry. Therefore, one of the alternatives for evaluating the efficiency of the economic system implies finding an effective way of solving these types of problems.

If we apply these basic definitions of trust to the operations of firms, trust is a reduction of the uncertainty that characterizes the relations of interdependence between individuals (agency relations). This bond is defined by the existence of mutuality that can be expressed by the interdependence of individual utility functions between subjects (sympathy). This relation generates cooperative behaviors, even if the actions carried out are of a concealed nature. Therefore, in this situation the firm would not need to monitor behaviors nor the alignment of preferences proposed by the Agency Theory, as the sympathetic links are able to provide it socially.

Given these characteristics, trust is a "merit good" that is especially present in the familiar unit (Becker, 1991), and as 
a result, family enterprises have a comparative advantage. However, we can find diverse forms of trust that must be analyzed and, at the same time, a conflictive process in their evolution that implies a necessary investment of resources for sustaining this advantage as the company expands.

\subsection{Bases and Effects of Trust}

According to Lewicki and Bunker (1996), trust can be built on three bases: calculation, knowledge or identification. Whereas the first is based on a fear of the consequences of the rupture, knowledge-based trust is based on the capacity to predict the behavior of others, and therefore on the information that is available. Both kinds of trust are "non-tuistic" or "egoistic" and fragile sources, since the motivation is associated with the preservation of one's own interests or the avoidance of some type of punishment, which would not be compensated by the force exerted by an opportunistic behavior (Arregle et al., 2007).

These first two types of trust make it necessary to deal with the monitoring costs of the tasks carried out by agents, or "to align" the incentives of the principal and the agents through compensation contracts. This is the proposal of the Agency Theory. However, this theory is a partial solution, insofar as it concentrates on the hierarchic relations between stockholders and managers, doing without the bonds between intermediate members of an organization. For these members, the strategies of this theory are expensive and ineffective, since for an intermediate level of organization, the connection between effort and evolution of the stock value are very fuzzy. Also, these strategies can be aggressive, expensive and, in many cases, impossible (Chami and Fullenkamp, 2002; Chami et al., 2002) ${ }^{1}$.

Nevertheless, the third base of trust or identification arises when both parts understand the intentions and preferences of the

1 Whatever the case, the solution provided by the Agency Theory is undoubtedly preferable to establishing a coercive external mechanism. 
other, or in other words when an alignment of preferences occurs which is motivated by the existence of commonly shared values. This third or "tuistic" expression constitutes trust in the strictest sense and has a more permanent character (Dess and Shaw, 2001; Pena and Sanchez, 2005). In these three sources of trust, rational and emotional components are combined. Nevertheless, the rational components seem to predominate in the non-tuistic expression, the emotional and moral components are essential in the third, and are especially characteristic of family bonds (Rousseau et al., 1998; Nooteboum, 2000) (Table 1).

Table 1: Sources of trust.

\begin{tabular}{lll} 
& \multicolumn{1}{c}{ Sources } & \multicolumn{1}{c}{ Instruments } \\
\cline { 2 - 3 } Non-tuistic & $\begin{array}{l}\text { Coercion by authority. } \\
\text { Search for advantages or } \\
\text { material interest. }\end{array}$ & $\begin{array}{l}\text { Third-party certifications, } \\
\text { external evaluation. } \\
\text { Systems of incentives. }\end{array}$ \\
\hline \multirow{2}{*}{ Tuistic } & $\begin{array}{l}\text { Ethics, values and norms } \\
\text { of behavior. }\end{array}$ & $\begin{array}{l}\text { Familiarity, community } \\
\text { common culture, friendships, } \\
\text { commitment. }\end{array}$ \\
\hline
\end{tabular}

Source: Authors' own elaboration.

As already mentioned, the tuistic forms are built on values, norms or standards of conduct and, at the same time, on individual interactions and the constitution of communities rooted in cultural affinities or social bonds. However, the ethical character of this kind of trust does not mean that it is "blind", as sympathetic relations also have a dialectic character or demand some form of reciprocity (Williams, 1988). In the same sense, this trust cannot be standardized or established contractually, and so the establishment of a contractual relation could even be destructive and become a self-fulfilling prophecy of its destruction. 
Apartfrom the two previous solutions, theory has traditionally relegated the capacity of ethical codes to avoid or overcome these agency problems. Ethics is a simpler and superior way of resolving economic conflicts, insofar as it supposes a reduction of transaction costs, favors group cohesion and constitutes a system of pre-coordination of individual decisions which precede the market. As Habermas indicates "morals allow the members of a group to expect certain actions from others in given situations, and force them to fulfill the expectations of behavior justified by the other" (Habermas, 1986; 51). Focusing on this concept, we are referring to the dispositions and capacities that lead us to mutual understanding and agreement as basic mechanisms for the satisfaction of interests and the consensual resolution of conflicts. These shared ethical codes, as previously mentioned, are the expression of the tuistic form of trust and, to a certain extent, could more properly be denominated as a type of moral capital.

In spite of the apparent clarity of these distinctions, it is necessary to stress that this typology, frequently found in studies on trust and social capital, is to some extent naïve. The reciprocal tuistic trust, typical of family enterprises, established in sympathy or interdependence of utility functions, can be ambivalent (Hardin, 1999). On the one hand, it makes it possible to overcome problems of cooperation caused by situations similar to the "Prisoner's Dilemma", and therefore facilitates a system of social precoordination (Warren, 1999). However, on the other hand, it could create networks based on sympathy relations and common objectives that facilitate the breaking of norms and form stable structures of corruption. This variant can be referred to as "particularistic trust" and creates bonds between the agents that are analogous to the generalized bond between any social agents, but with the opposite effects. We could even speak, in terms of the theory of the Raccomandazione, of overlapped forms of corruption in the political and economic culture of the society, or "amoral familism" (Uslaner, 2005; Lambsdorf, 2002). The difference between theses expressions of reciprocal trust is rooted in the 
universalistic ethical principles of the first, contrasted with the particularistic ethic principles of the second.

With regard to the effects, it is obvious that in a situation of trust the behaviors are predictable, and so the monitoring and transaction costs are reduced. On a macro scale, as Arrow (1972) affirms, virtually all economic transactions require the existence of a trust substrate, and is reasonable that all forms of economic underdevelopment can be explained by the absence of mutual trust. On a micro scale, the generation of a cooperative climate within the workforce of any company based on trust relations constitutes, doubtlessly, one of the key tasks.

In short, trust is a way of reducing uncertainty by generating information to tackle the problem of opportunistic behaviors, namely an informal mechanism of management and alternative government to the systems based on rewards or some form of authority (Bradach and Ecless, 1989). In the case of family-run companies, its characteristic trust corresponds to reciprocal tuistic forms, and its foundations based on identification and sympathy relations, although it may also have an ambivalent character.

\subsection{Trust in family firms}

The basic singularity of a family company is the influence of family relations on the economic activity, specifically in the way the organization is managed, structured and transferred. In fact, family relations could generate a motivation, bonds of fidelity to the company and increase trust, thereby reducing transaction costs, although the causality is ambiguous (Tagiuri and Davis, 1996). While "social capital" is the term used to identify the resources that exist in individual and collective relations, the notion of family capital emphasizes the importance of family networks to facilitate the extension of trust by means of family relations.

In particular, a family system is characterized by cohesion, flexibility and communication (Figure 4). Cohesion implies a 
certain form of closure that guarantees a strong connection between the members. Flexibility alludes to the capacity of interchange of social and entrepreneurial roles between members, whereas communication expresses the existing bonds of respect and obedience that guarantee the absence of shirking and reserved utility.

Figure 4: Family system and family enterprise.

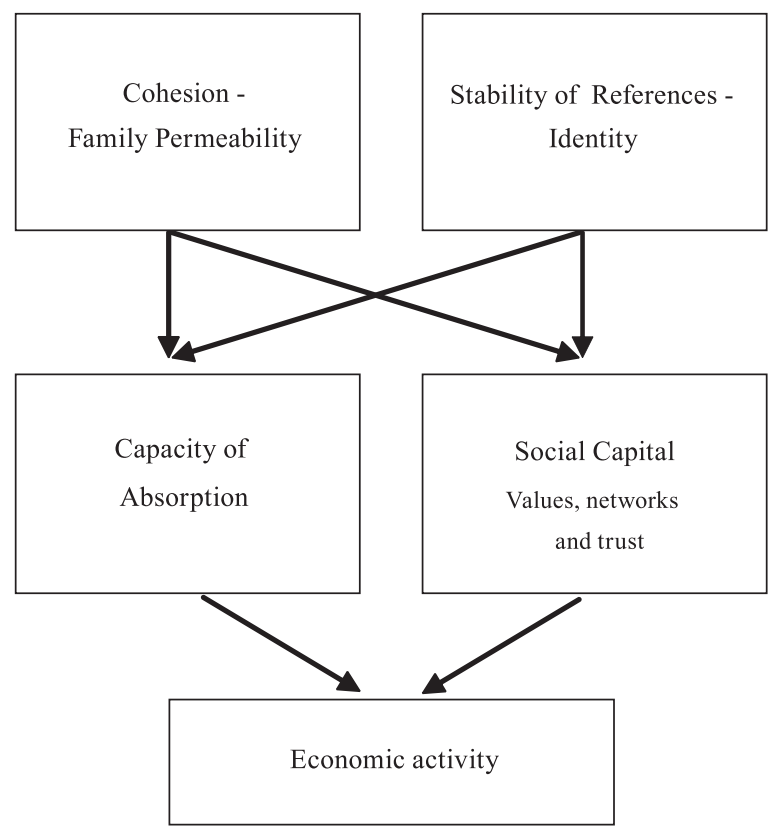

Source: Authors' own elaboration.

Consistently, trust is an essential dimension of family firms, since its differential character lies in the presence of bonds between the members of the company, whether they are relatives or not, that go beyond economic interests. These networks of relations, obligations and expectations are translated into the generation of collective trust, i.e. a convergence of expectations or a shared common code. 
This common code can also be present in non-family companies, but is reinforced in this case by the reference to a model of administration of a common ancestor or background and a certain familiar identity (Corvetta and Salvato, 2004). This construction of an identity and a shared code ("we-rationality") in a more favorable context makes it possible to endow the company with a sustainable advantage that results in a greater success in the long term.

Common identity and shared values, sympathy relations and trust permit cooperation, promoting networks of relations and reducing conflicts. However, in the case of family-run companies, we find an additional benefit: absorption. This signifies an organizational routine through which the companies introduce, assimilate and adapt knowledge. This is a team-form of learning that the company can use for its objectives, and is based on the internal and external interactions of the agents. The strong bonds that are typical of a family company organization permit an almost altruistic transmission of information that provides them with a sustainable advantage in terms of creative capacity and adaptation to new contexts. Put simply, agents choose to do without their utility of reserve. However, this use of the term "identity" is excessively simplistic. It is necessary to consider the distinguishing features of the generated trust and to analyze its evolution in the organization in its process of growth and adaptation.

\section{Evolution and Transmission of Social Capital in Family Firms}

\subsection{Evolution of Social Capital within Family Companies}

The peculiarities of social capital within family-run firms discussed in the previous sections provide a better understanding of the parallel evolution of this form of capital 
and the growth and development of these companies. This parallel process is clearly reflected in the evolution of the three dimensions involved (values, networks and trust), which in turn influence the sustainability of the potential comparative advantage of these types of firms. Therefore, the accumulation and dissipation of social capital can be seen as a dynamic process, and also as a regenerative cycle, whereby the family-run company is in a constant process of recreating the foundations over which trust, values and networks are based. Moreover, according to one of Luhmann's assumptions (1979), trust, and social capital by extension, require distrust for their development. The evolutionary character of social capital can differ depending both on the company and on whether internal or external relations are considered. However, despite the differences seen in family firms, at least three different stages can generally be distinguished in the above mentioned process. The characteristics of the different levels can be described as follows.

The first stage corresponds to the starting point of familyrun companies. In this stage, these firms are endowed with high levels of social capital, essentially based on relations of an interpersonal nature (Corvetta and Salvato, 2004). In terms of trust, this phase is based on affinity or communality, a common history or a long period of common experiences between members of the company (Steward, 2003). In a general way, communality fortifies the cognitive and emotional foundations of the interpersonal trust in the predictability of the actions of the other, and in the emotional bonds that they facilitate. Individuals put themselves in the place of the other (sympathy networks) and are identified with a set of norms. As a result, this kind of trust is based on identification and interpersonal networks (Sundaramurthy, 2008). This first stage is characterized in evaluative terms by the high consistency of core values and general aims, which are also translated in a high organizational cohesion. Therefore, a certain predominance of the relational family network against the firm or organizational network seems to emerge in this stage. 
Family-run companies therefore begin with a high level of interpersonal trust since the family is a common factor of identification in values and in objectives, and provides a basic network of trust. Consequently, the company can count on the contribution and commitment of a substantial number of its members and even certain forms of altruism with regard to the overall well-being of the family and, by extension, of the company (Gersick et al., 1997). However, situations of this kind can give rise to forms of blind trust and we-rationality that would be dysfunctional insofar as they destroy the necessary quest for profit. Supported by the initial success that the community of interests generates, the family could constantly seek consensus, which erodes the quality of the decision-making process and the ability to compete in the market. In this case we can find a paradox, whereby trust, networks and values must make it possible to reduce the transaction costs caused by the potential conflicts, but they do not have to eliminate the functional conflicts that constrain the capacity of the company in its adaptation to changes.

Also, stagnation in this first phase may be a serious obstacle to the growth of the company, as long as it hinders the integration of new individuals into the organization. At the same time, changes in market conditions, competitors and stakeholders call for constant changes in its activity. As the company grows, the family is extending its implication in the company to a more extensive nucleus. The lack of knowledge among the members of the structure supposes a change in the management style, and the necessity of developing a new way of trust evolving the dominant values and the firm's networks.

The second stage, competential social capital is associated with a trust in the capacity or competence of organization's members. Then, it is the belief that the parts involved in the development of a task are not only capable, but their will is to develop the work in an effective and efficient way (Mishra, 1996). This kind of trust starts to expand at the moment at which the family firm is opened to external influence, enabling the company to establish bonds with the exterior. This change 
is critical for guaranteeing the survival of the company (Ward, 2004). New agents can clarify the role of the family in order to determine which are its identitary characteristics and what the strategy of the family is. At the same time, they act as catalyst for trust, building bridges with subordinates and within the family, and even bringing a new degree of transparency to the activities carried out by the management. This trust can also be obtained as a result of young people acquiring professional experience outside of the company. Consistently, external success and the experience gained by the employees before adhering to the company can be decisive for the growth of the family firm. In the same way, the creation of a framework of communication and collaboration in the access to information, learning and the generation of resources helps in adapting to new contexts.

In terms of networks, a potentially conflicting overlapping of systems occurs in all family companies (Taguri and Davis,1996). On the one hand, some separated nuclei of the family that could prefer other managerial trajectories exist, and on the other hand, the bonds of the company with stakeholders and, in particular, the system of the employees who are not bound to the family. In this sense, clarifying the expectations of the different systems with regard to their role in the evolution of the company can be decisive, namely through clear policies in terms of admission, succession, compensation and promotion.

Finally, systemic social capital usually appears as a third stage. This evolution of familiness expresses the collective features of an administrative organization and its management, which are not reducible to individual actors and which ensure continuity when these disappear. This means that it is institutional in nature, and is linked to the trust that the individuals deposit in systems and proceedings, and is practically extended to the company's stakeholders. At this point a bond may appear with the formal traditions and rules that have identified the company, as these constitute a fundamental reference at the time of establishing institutional trust (Sydow, 1998). The logical consequence is that the transparency of rules and established traditions and 
the supply of information to the agents, directly affected by the management of the company, is "conditio sine qua non" for this change, as this is the base of the trust in the system.

Reaching this phase without the dissolution of the stock of family social capital depends directly on the fairness of procedures. In this sense, Heyden et al. (2005) refers to five precise and essential features in this evolution: to give voice to all the stakeholders involved, clarity of information, procedures and expectations, consistency of the decisions with the past, possibility of changes in the policies based on clear mechanisms and the existence of a "commitment to fairness".

Therefore, family companies can enjoy competitive advantages based on trust as long as the initial interpersonal trust can be complemented by structures and procedures that maintain the systemic and competential trust, and both require the policies that are applied to be transparent and consistent (see Figure 5 below).

Figure 5: Evolution of social capital in the family company.

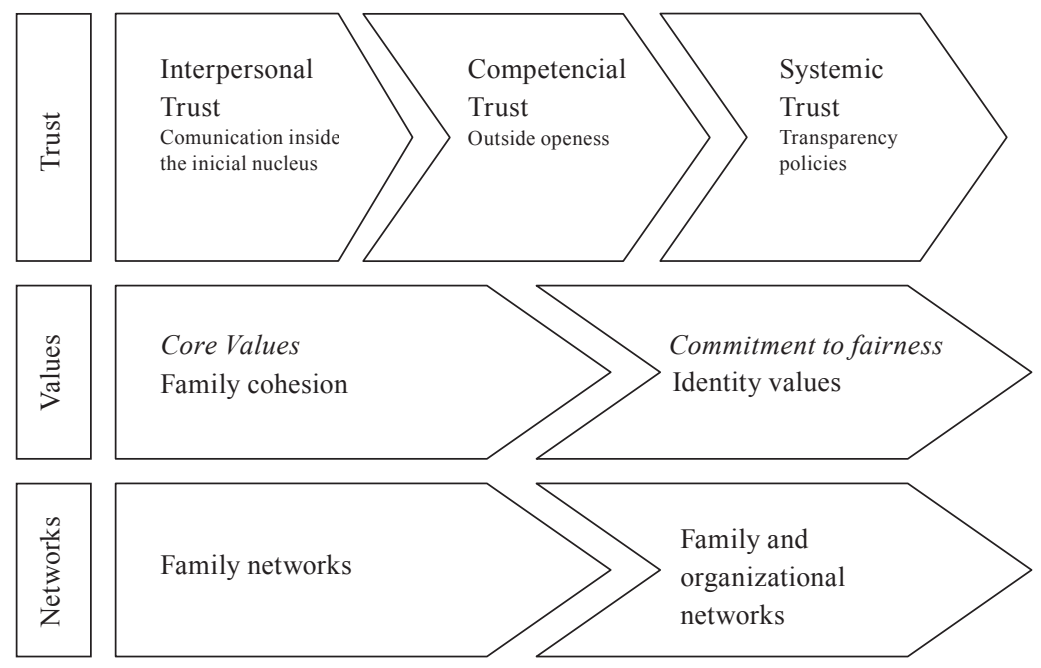

Source: Authors' own elaboration. 


\subsection{Intergenerational Transfer of Social Capital}

In general, firms accumulate social capital over time, and a necessary condition for accumulation is intergenerational transmission. Salvato and Melin (2008) discuss the relevant role played by family-related social capital components in shaping a family firm's trans-generational value-creation profile. Although social capital enhances value creation in any type of firm, in a family business the specificity comes from the fact that these advantages are absorbed in the social links of family members and in the configuration of the family network, and therefore can be more easily sustained over successive generations.

Prior to the succession process, the family's social capital can play a role in determining the attitude of the next generation towards the family firm. Lee (2006) highlights the fact that family relationships (more precisely the dimensions of family cohesion and family adaptability which were explained in the section dedicated to networks) do have a substantial influence on the attitudes and behaviors of the second generation working in family businesses. More specifically, he shows that family adaptability is a valuable asset in family businesses, as it significantly affects the work satisfaction and organizational commitment of the second generation. On the other hand, the author states that family cohesion has a limited or insignificant effect on the commitment and satisfaction levels of the second generation.

An example of this can be found in García-Álvarez et al. (2002), who study a group of Spanish family firms. These authors observe that the founder's view of the business influences the mode and process of socialization they use for the next generation of family members. Those who view their business as a means of supporting the family, value the feeling of family, limit the growth of their firms and incorporate the successors at a lower position and with low levels of formal education. On the other hand, founders who view the family firm as an end in itself encourage successors to achieve high levels of formal education and experience outside the business before joining the firm. 
Steier (2001) points out that in the case of firms that are already established, a central task is to pass on the key resources residing within this network to the next generation. Within the context of family firms and succession, social capital represents one of the least tangible and least fungible assets, and it is not easily traded or transferred. This can be due to several reasons. In some cases personal and professional circumstances impede an accurate transmission and, in other cases the agents who are involved do not implement the appropriate mechanisms to transfer it. In this sense, Cabrera et al. (2001) suggest that the performance of the next generation is likely to be based on the effectiveness with which these cognitive structures, common schemes, family and professional contacts are transferred across generations. Here it is important to note that in general, family businesses are characterized by less formal ways of operating and generally, less formalized policies and rules than non-family firms, taking into account the fact that knowledge of network structures is frequently tacit and not easily communicated. As Sharma (2004) states, "due to their long tenures, family firm leaders posses a significant amount of idiosyncratic or tacit knowledge related to the firm".

Steier's work systematizes the ways in which this transfer can be made depending on the type of succession: unplanned, sudden succession when unanticipated events call for another family member to take over a management role at short notice; rushed succession, when circumstances force the family to make previously unanticipated management changes ; natural immersion, when the successor gradually assimilates the nuances of network structure and relationships; and planned succession and the deliberate transfer of social capital.

Also, the same study refers to seven ways of managing social capital: deciphering or interpreting existing network structures; deciphering the transactional content of network relationships; determining criticalities, by determining which relationships are the most critical for the survival and success of the firm, and taking steps to ensure their continuation; attaining legitimacy in the new tasks and roles within the network; clarifying the 
optimal role of the successor in the family's and firm's networks; managing ties through delegation and division of labor; and striving for optimal network configuration and reconstituting network structure and content.

Another important point in this issue is that owners derive value from passing on the legacy of the enterprising family tradition, emotional bonds between family members, and nostalgia (Sharma and Manikutty, 2005). Cultural beliefs may also underlie the decision to build a family legacy, and instill the desire to ensure survival and family control at all cost. This objective may not always be in line with the most suitable long-term strategy, especially if it leads families to display an excessive aversion to risk or to forgo profitable expansion strategies or mergers with other firms (Bertrand and Schoar, 2006). Therefore, suboptimal economic organization can emerge when parents put too much emphasis on keeping the business in the family, either as a result of a strong sense of duty towards other family members, or a more selfish desire to turn the business into family legacy.

One interesting area where family firm networks can be crucial for the company's future prospects is mentoring, i.e. the creation of a figure who is responsible for designing and monitoring the training process of the candidates for succession. Depending on the characteristics of the family and the firm, the mentor should be a person who has a relevant position in both networks, the firm's and the family's, as their success will largely depend on the existing credibility and trust in their actions. The capacity to improve the experience and suitability of the candidates could depend on the existence of links and relationships with other firms and institutions.

\section{Conclusion}

This chapter reviews the components of social capital in family firms, in order to establish the mechanisms that connect and interlace family and business systems with each other. 
In our opinion, this decomposition sheds light on some of the singularities of family firms that are commonplace in the literature, such as the role of values and commitment, entrepreneurial networks or the role of trust.

Research into this topic within the context of family-owned and managed firms is frequently lost in circular causalities on the nature and components of the concept and, in particular, which features may help to explain under which conditions social capital can be seen as a strategic advantage or disadvantage in family enterprises. For family firms, competitive advantages or disadvantages could be derived from a balanced or imbalanced flow between family social capital and organizational social capital. In other words, the characteristics of the interaction between family and firm, in terms of the respective values, networks and trust of each system, encourage the generation of both positive and negative social capital. 


\section{References}

Adler, P. S. and Kwon, S. (2002): "Social capital: Prospects for a new concept", Academy of Management Review, 27(1), 17-40.

Anderson, A. R. and Jack, S. L. (2002): “The articulation of social capital in entrepreneurial networks: a glue or a lubricant?", Entrepreneurship \& Regional Development, 14, 193-210.

Anderson, A. R., Jack, S. L. and Drakopoulou, S. (2006): "The role of family members in entrepreneurial networks: Beyond the boundaries of the family firm", Family Business Review, vol XVIII, n. 2, 135-154.

Anderson, R. C. and Reeb, D. M. (2003): "Founding-Family Ownership and Firm Performance: Evidence from the S\&P 500", Journal of Finance, 58(3), 1301-1329.

Aronoff, C. and Ward, J. L. (1995): "Family-owned business: a thing of the past or a model of the future?", Family Business Review, 8 (2), 121-130.

Arregle, J. C., Durand, R. and Very, P. (2003): "Origines du capital social et avantages concurrentiels des firmes familiales”, $M @$ na@gement, 7,1, 13-36.

Arregle, J. C., Hitt, M. A., Sirmon, D. G. and Very, P. (2007): "The development of organizational social capital: Attributes of family firms", Journal of Management Studies, vol. 44, n. 1, 73-95.

Arrow, K. (1972): "Gifts and exchanges", Philosophy and public affairs, I, 343-362.

Athanassiou, N., Crittenden, W. F., Kelly, L. M. and Márquez, P. (2008): "Founder centrality effects on the mexican family firm's top management group", Journal of World Business, vol. 37, n. 2, 139-150.

Banfield, E. (1958): The Moral Basis of A Backward Society. New York: Free Press.

Becker, G. (1991): A treatise on the family. Cambridge, Massachusetts, Harvard University Press.

Berger, P. and Luckman, T. (1967): The Social Construction of Reality: A Treatise in the Sociology of Knowledge. London: Penguin Press. 
Bertrand, M. and Schoar, A. (2006): "The Role of Family in Family Firms", Journal of Economic Perspectives, 20, 2, 73-96.

Bourdieu, P. (1994): Raisons Pratiques. Sur la théorie de l'action. Paris: Seuil.

Bowley, J. L. and Easton, G. (2007): “Entrepreneurial social capital unplugged. An activity-based analysis", International Small Business Journal, 25, 3, 273-306.

Bradach, J. L. y Eccles, R. G. (1989): "Price, authority and trust: from ideal types to plural forms", Annual Review of Sociology, 15, 97-118.

Bubolz, M. (2001): "Family as Source, User, and Builder of Social Capital”, Journal of Socio-Economics, 30(2), 129-131.

Cabrera-Suárez, K., De Saá-Pérez, P. and García-Almeida, D. (2001): "The succession process from a resource- and knowledge-based view of the family firm", Family Business Review, 14, 1, 37-48.

Casanueva, C. and Galán, J. L. (2004): "Social and information relations in networks of small and médium-sized firms", $M @$ n@gement, vol. 7, n.3, 215-238.

Chami, R. and Fullemkamp, C. (2002): "Trust and efficiency", Journal of banking and finance, 26 (2002), 1791-1820.

Chami, R., Cosimano, T. F. and Fullemkamp, C. (2002): "Managing ethical risk: how investing in ethics adds value", Journal of Banking and Finance, 26, 1697-1718.

Coleman, J. S. (1988): "Social capital in the creation of human capital”, American Journal of Sociology, 94, S95-S120.

Coleman, J. (1990): Foundations of Social Theory. Cambridge, MA: Harvard University Press.

Corvetta, G. and Salvato, C. (2004): "Self-serving or self actualizing? Models of man and agency cost in different types of family firms", Entrepreneurship Theory and Practice, 28, 355-362.

Davies, P. W. F. (1997): Current Issues in Business Ethics. New York: Routledge.

Denison, D., Lief, C. and Ward, J. L. (2004): "Culture in FamilyOwned Enterprises: Recognizing and Leveraging Unique Strengths", Family Business Review, vol. XVII, n. 1, 61-70. 
Dess, G. D. and Shaw, J. D. (2001): "Voluntary turnover, social capital, and organizational performance", Academy of Management Review, 26, 3, 446-56.

Dumas, C. and Blodgett, M. (1999): "Articulating Values to Inform Decision Making: Lessons form Family Firms Around the World", International Journal of Value-Based Management, 12, 209-221.

Durlauf, A. N. and Fafchamps, N. (2004): Social capital, NBER Working Paper 10485.

Fukuyama, F. (1995): Trust, the social virtues and the creation of prosperity. New York: Free Press.

Fukuyama, F. (2000): "Social Capital and Civil Society", IMF Working Paper, WP/00/74.

García-Álvarez, E., López-Sintas, J. and Saldaña-Gonzalvo, P. (2002): "Socialization paterns of successors in first-and second-generation family businesses", Family Business Review, 15, 3, 189-203.

Gersick, K., Davis, J., McCollon, M. and Lansberg, I. (1997): Generation to generation. Boston: Harvard Business School Press.

Granovetter, M. (1973): “The strength of weak ties", American Journal of Sociology, 78, 6, 1360-1380.

Habermas, J. (1986): Teoría de la acción comunicativa. Madrid: Taurus.

Hardin, R. (2001): "Gaming trust", in Olstrom, E. and Walker, J. (eds.): Trust and reciprocity: interdisciplinary lessons from experimental research. New York: Rusell Sage Foundation.

Heyden, L., Blondel, C. and Carlock, R. S. (2005): "Fair process: striving for justice in family business”, Family Business Review, 18, 1, 1-21.

Hoffman, J., Hoelscher, M. and Sorenson, R. (2006): "Achieving sustained competitive advantage: A family capital theory", Family Business Review, vol. XIX, n. 2, 135-145.

Jack, S. (2005): "The role, use and activation of strong and network ties: A qualitative analysis", Journal of Management Studies, vol. 42, n. 6, 1233-1259. 
Kelly, L., Athanassiou, N. and Crittenden, W. F. (2000): "Founder centrality and strategic behaviour in family-owned firm", Entrepreneurship Theory and Practice, Winter, 27-42.

Kepner, E. (1983): "The family and the firm: A Coevolutionary Perspective”, Organizational Dynamics, 12(1), 57-70.

Kotter, J. and Heskitt, J. (1992): Corporate culture and performance. New York: Free Press.

Kramer, R. M. (1999): "Trust and distrust in organization: Emerging perspectives, enduring questions", Annual Review in Psychology, 50, 60-98.

Lambsdorff, J. (2002): “Corruption and Rent-seeking”, Public Choice 113, 97-125.

Lane, C. (1998): "Introduction: Theories and issues in the study of trust", in Lane, C. and Bachmann, R. (eds.): Trust within and between organizations: conceptual issues and empirical applications. New York, NY: Oxford University Press, 1-30.

Lansberg, I. (1999): Succeeding generations. Boston: Harvard Business School Press.

Lee, J. (2006): "Impact of family relationships on attitudes of the second generation in family business", Family Business Review, vol. XIX, n. 3, 175-191.

Lewicki, R. and Bunker, B. (1996): "Developing and maintaining trust in work relationships", in Kramer, R. M. and Tyler, M. (eds.): Trust in organizations: frontiers of theory and research. Thousand Oaks, Sage, 114-139.

Luhmann, N. (1979): Trust and power. Chichester, Wiley.

Luhmann, N. (1988): "Familiarity, confidence and trust: problems and alternatives", in Gambeta, D. (ed.): Trust: making and breaking cooperative relations. New York: Blackwell, 94-108.

Mishra, A. K. (1996): "Organizational responses to crisis: the centrality of trust", in Kramer, R. M. and Tyler, M. (eds.): Trust in organizations: frontiers of theory and research. Thousand Oaks, Sage, 261-287.

Nahapiet, J. and Ghoshal, S. (1998): "Social capital, intellectual capital and the organizational advantage", Academy of Management Review, 23, 242-267. 
Nooteboom, B. (2000): "Trust as a governance device", in Casson, M. and Godley, A.: Cultural factors in economic growth. Heidelberg: Springer.

Olson, D. H. (1986): "Circumplex Model VII: Validation Studies and FACES III", Family Process, 25(3): 337-351.

Paldam, M. (2000): "Social capital: one or many? Definition and measurement", Journal of Economic Surveys, 14, 5, 629-653.

Parsons, T. (1949): The structure of social action: a study in social theory with special reference to a group of European writers. $2^{\text {nd }}$ ed. Free Press. New York.

Pearson, A. W., Carr, J. C. and Shaw, J. C. (2008): "Toward a Theory of Familiness: A social perspective", Entrepreneurship Theory and Practice, 32, 6, 949-969.

Pena López, J. A. and Sánchez Santos, J. M. (2006): "Altruismo, simpatía y comportamientos prosociales en el Análisis Económico", Principios: Estudios de Economía Política, $n^{\circ} 4,55-70$.

Portes, A. (1998): "Social Capital: Its Origins and Applications in Modern Sociology”, Annual Review of Sociology, 24, 1, 1-24.

Putnam, R. (1993): Making Democracy Work: Civic Traditions in Modern Italy. Princeton, N.J.: Princeton University Press.

Rousseau, D., Sitkin, S. B., Burt, B. R. and Camerer, C. (1998): "Not so different after all: a cross discipline view of trust", Academy of management review, 23, 405-421.

Salvaj, E., Ferraro, F. and Tàpies, J. (2008): "Family firms and the contingent value of board interlocks: The spanish case", in Tàpies, J. and Ward, J. (eds.): Family values and value creation. Palgrave Macmillan.

Salvato, C. and Melin, L. (2008): "Creating value across generations in family-controlled businesses: The role of family social capital”, Family Business Review, vol. XXI, n. 3, 259-276.

Schul, Y., Mayo, R. and Bursntein, E. (2008): "The value of distrust” Journal of Experimental Social Psychology, Vol. 93, n. 3, 593-601.

Sharma, P. (2004): "An overview of the field of family business studies: Current status and directions for the future", Family Business Review, 17, 1, 1-36. 
Sharma, P. (2008): "Familiness: Capital stocks and flows between family and business", Entrepreneurship Theory and Practice, 32, 971-977.

Sharma, P., Chrisman, J. J., and Chua, J. H. (1997): "Strategic management of the family business: Past research and future challenges", Family Business Review, 10, 1-36.

Sharma, P. and Manikutty, S. (2005): "Strategic divestments in family firms: Role of family structure and community culture", Entrepreneurship Theory and Practice, 29, 293-311.

Silva, F., Majluf, N. and Paredes, R. (2006): "Family ties, interlocking directors and performance in business groups in emerging countries: The case of Chile", Journal of Business Research, vol. 59, n. 3, 315-321.

Sorenson, R. L. (1999): "Conflict strategies used by successful family businesses”, Family Business Review, 12, 4, 325-339.

Steier,Ll. (2001): "Next-generation entrepreneurs and succession: An exploratory study of modes and jeans of managing social capital", Family Business Review, 24, 3, 259-276.

Steward, A. (2003): "Help one another, use one another: Toward anthropology of family business", Entrepreneurship Theory and Practice, 27, 383-396.

Sundaramurthy, Ch. (2008): "Sustaining trust within family businesses", Family business review, vol. XXI, 1, 89-102.

Sydow, J. (1998): "Understanding the constitution of interorganizational trust", in Lane, I. C. and Bachmann, R. (eds.): Trust within and between organizations. New York: Oxford University Press.

Taguri, R. and Davis, J. (1996): "Bivalent attributes of the family firm”, Family Business Review, 9, 199-209.

Torsvik, G. (2000): "Social Capital and Economic Development", Rationality and Society, 12, 4, 451-476.

Tsai, W. and Ghoshal, S. (1998): "Social Capital and Value Creation: The Role of Intrafirm Networks", The Academy of Management Journal, Vol. 41, N. 4, 464-476.

Uphoff, N. (1998): "Understanding social capital: learning from the analysis and experience of participation", in Serageldin, I. and Dasgupta, P. (eds.): Social Capital. Oxford: Oxford University Press. 
Uphoff, N. (2000): “Understanding social capital: learning from the analysis and experience of participation", in Dasgupta, P. and Serageldin, I. (comps.): Social Capital: A multifaceted perspective. Washington, D.C.: The World Bank.

Uslaner, E. (2005): “Trust and Corruption”, in Lambsdorff, J., Taube, M. and Schramm, M. (eds.): The New Institutional Economics of Corruption. New York: Routledge.

Uzzi, B. (1997): "Social Structure and Competition in Interfirm Networks: The Paradox of Embeddedness", Administrative Science Quarterly, 42, 35-67.

Vallejo, M. C. (2008): "Is the Culture of Family Firms Really Different? A Value-based Model for Its Survival through Generations", Journal of Business Ethics, 81, 261-279.

Ward, J. L. (1997): "Growing the Family Business: Special Challenges and Best Practices", Family Businesses Review, 10(4): 323-337.

Ward, J. L. (2004): Perpetuating the family business. New York: Macmillan.

Warren, M. (1999): "Democratic Theory and Trust", in Warren, M.: Democracy and Trust. Cambridge: Cambridge University Press, 310-345.

Weber, M. (1904): The Protestant Ethic and the Spirit of Capitalism. New York: Scribner's Press.

Westhead, P. and Cowling, M. (1997): "Performance contrasts between family and non-family unquoted companies in the UK", International Journal of Entrepreneurial Behaviour and Research, 3, 30-52.

Williams, B. (1988): "Formal structures and social reality", in Gambetta, D. (ed.): Trust; making and breaking cooperative relations. Oxford: Blackwell, 453-486.

Woolcock, M. (2001): Using Social Capital: Getting the Social Relations Right in the Theory and Practice of Economic Development. Princeton, NJ: Princeton University Press.

Zellweger, T. M. and Astrachan, J. H. (2008): "On the Emotional Value of Owning a Firm", Family Business Review, vol. XXI, n. 4, 347-363. 
- 
- 
- 